\title{
FAKTOR-FAKTOR YANG MENYEBABKAN KEGAGALAN IBU DALAM MEMBERIKAN ASI EKSLUSIF PADA BAYI USIA 0-6 BULAN DI WILAYAH KERJA PUSKESMAS PEJERUK
}

\author{
Cahaya Indah Lestari", Aulia Amini, Nurul Qamariah Rista Andaruni, Nita Helena Putri
}

*Prodi D3 Kebidanan, Universitas Muhammadiyah Mataram, cahayaisnaini2011@gmail.com

\section{INFO ARTIKEL}

Riwayat Artikel:

Diterima: 09-11-18

Disetujui: 14-01-19

\section{Kata Kunci:}

Faktor-faktor

Penyebab Kegagalan

Asi Ekslusif

\begin{abstract}
Abstrak: Target cakupan ASI eksklusif oleh Depkes RI sebesar 80\%, sedangkan tahun 2013 cakupan ASI Eksklusif di Indonesia hanya 54,3\%, Provinsi Nusa Tenggara Barat tahun 2015 mencapai cakupan ASI Eksklusif 74,7\%, dan Puskesmas Pejeruk adalah puskesmas dengan angka cakupan ASI Eksklusif terendah yaitu 66,22\%. Tujuan penelitian ini adalah mengetahui faktor-faktoryang menyebabkankegagalanibudalam memberikan ASI Eksklusif pada bayi usia 0-6 Bulan. Metode Penelitian ini adalah penelitian deskriptif dengan tekhnik pengambilan purposive sampling. Hasil: 1) Berdasarkan faktor umur yaitu <20th 5 orang (14,71\%), 20-35th 20 orang $(58,82 \%)$, $>35$ th 9 orang $(26,73 \%)$; 2) Berdasarkan faktor paritas yaitu primipara 16 orang (47,06\%), multipara 17 orang (50\%), grandemultipara 1 orang (2,94\%); 3) Berdasarkan faktor pendidikan yaitu pendidikan dasar 17 orang (50\%), pendidikan menengah 11 orang (32,35\%), pendidikan tinggi 6 orang $(17,65 \%)$; 4) Berdasarkan faktor pengetahuan yaitu baik 16 orang (47,06\%), cukup 15 orang (44,12\%), kurang 3 orang (8,82\%); 5) Berdasarkan faktor dukungan yaitu baik 7 orang (20,59\%), cukup 25 orang (73,53\%), kurang 2 orang (5,88\%). Simpulan dan saran: Penyebab kegagalan ASI Eksklusif yang paling dominan adalah karena faktor pendidikan dimana terdapat 17 responden dengan pendidikan dasar yang tidak memberikan ASI Eksklusif. Diharapkan instansi kesehatan khususnya Puskesmas Pejeruk dapat selalu memberikan penyuluhan mengenai ASI Eksklusif dengan menggunakan bahasa yang mudah dimengerti oleh masyarakat awam agar dapat menekan angka kegagalan ASI Eksklusif dan dapat memenuhi angka yang ditargetkan oleh Depkes RI.
\end{abstract}

ABSTRAK

Abstract: Target exclusive breastfeeding coverage by Depkes RI by 80\%, whereas in 2013 coverage of exclusive breastfeeding in Indonesia, only 54.3\%, West Nusa Tenggara province in 2015 reached $74.7 \%$ coverage of exclusive breastfeeding, and Pejeruk health centers are health centers with numbers coverage Exclusive breastfeeding lowest at 66.22\%. To determine the factors that led to the failure of the mother in exclusive breastfeeding in infants aged 0-6 months. This research is a descriptive research with purposive sampling technique. The results showed as follows: 1) Based on the age factor is <20th 5 votes (14.71\%), 20-35th 20 (58.82\%), > 35th 9 (26.73\%); 2) Based on the parity factor is primiparas 16 people (47.06\%), multiparous 17 people (50\%), grandemultipara 1 (2.94\%); 3) Based on the factors, namely education basic education 17 people (50\%), secondary education 11 people (32.35\%), higher education 6 (17.65\%); 4) Based on the knowledge that is a good factor 16 (47.06\%), just 15 people (44.12\%), less than 3 (8.82\%); 5) Based on the factors that support either 7 (20.59\%), just 25 people (73.53\%), less than 2 (5.88\%). The cause of the failure of exclusive breastfeeding is the most dominant because of education where there were 17 respondents with primary education are not exclusive breastfeeding.Expected health institutions especially Puskesmas Pejeruk can always provide counseling on exclusive breastfeeding by using language that is easily understood by the public cloud in order to reduce the number of exclusive breastfeeding failure and can meet the targeted rate of Depkes RI. 


\section{A. LATAR BELAKANG}

Pemberian Air Susu Ibu (ASI) secara eksklusif merupakan pemberian ASI tanpa bahan makanan dan minuman tambahan lain pada bayi berumur nol sampai enam bulan. Makanan atau minuman lain yang dimaksud misalnya seperti susu formula, jeruk, madu, air teh, atau pun makanan padat seperti pisang, pepaya, bubur susu, biskuit, bubur nasi dan tim bahkan air putih pun tidak boleh diberikan (Roesli, 2007).

ASI merupakan salah satu makanan yang sempurna dan terbaik bagi bayi karena mengandung unsur-unsur gizi yang dibutuhkan oleh bayi untuk pertumbuhan dan perkembangan yang optimal. Pemberian ASI perlu diberikan secara eksklusif sampai anak berumur 6 bulan dan dapat dilanjutkan sampai anak berusia 2 (dua) tahun. Walaupun demikian masih terdapat kendala dalam pemantauan pemberian ASI eksklusif karena belum ada sistem yang dapat diandalkan untuk memantau pemberian ASI Eksklusif (Purwanti, 2008). Meskipun sebagian orang tua telah menyadari pentingnya memberikan ASI kepada bayinya, tetapi berbagai kendala masih ditemukan di masyarakat. Salah satunya adalah ketidak berhasilan ibu menyusui anaknya sampai usia 6 bulan secara eksklusif (Purwanti, 2008).

Merujuk pada laporan World Breastfeeding Trends Initiative 2012, Indonesia berada di peringkat 49 dari 51 negara yang mendukung pemberian ASI Eksklusif. Menurut World Health Organization (WHO) pada tahun 2012 hanya 36\% kelahiran bayi yang didunia yang mendapatkan ASI Eksklusif.Data Riset Kesehatan Dasar (Riskesdas) tahun 2013 menunjukkan cakupan ASI Eksklusif di Indonesia mencapai 54,3\% dari jumlah bayi usia 0-6 bulan atau secara absolute sebesar 1.348.532 bayi, dan sisanya tidak mendapatkan ASI Eksklusif yaitu sebanyak 1.134.952 bayi (Depkes RI, 2014). Provinsi Nusa Tenggara Barat pada tahun 2015 mencapai cakupan ASI Eksklusif sebesar 74,7\% (Dikes NTB, 2015). Berdasarkan data yang diperoleh dari Dinas Kesehatan Kota Mataram, cakupan ASI Eksklusif tertinggi di Kota Mataram yaitu di Puskesmas Selaparang sebanyak 82,70\%, dan cakupan ASI Eksklusif terendah yaitu di Puskesmas Pejeruk sebanyak 66,22\% (Dikes Kota Mataram, 2015).

Pemberian ASI yang tidak optimal mempengaruhi terjadinya $45 \%$ kematian akibat infeksi neonatal, 30\% kematian akibat diare dan $18 \%$ kematian akibat infeksi saluran pernafasan pada balita. Anak yang tidak disusui beresiko 14 kali akan mengalami kematian karena penyakit diare dan pneumonia, dibandingkan dengan anak yang mendapatkan ASI eksklusif (Roesli, 2007). Langkah yang telah diambil oleh Pemerintah Indonesia untuk meningkatkan angka cakupan ASI Eksklusif antara lain dengan disahkannya Peraturan Pemerintah mengenai ASI Eksklusif yang melarang promosi PASI di fasilitas kesehatan dan hak perempuan untuk menyusui. Pemerintah Indonesia juga memainkan peranan penting dalam Inisiatif Global Scaling Up Nutrition, yang berfokus pada upaya penting kebijakan yang terkoordinir dengan lebih baik dan memperkuat kemampuan teknis untuk meningkatkan status gizi anak termasuk pemberian ASI (Depkes RI, 2013).

Pemberian ASI Eksklusif merupakan pemenuhan terhadap hak anak. Hal ini sudah dijamin oleh peraturan perundangan yaitu PeraturanPemerintah (PP) No.33 Tahun 2012 Tanggal 1 Maret 2012 tentang Pemberian ASI Eksklusif. Pasal 128 Ayat 1 yang berbunyi, "Setiap bayi berhak mendapatkan ASI Eksklusif sejak dilahirkan selama 6 (enam) bulan”. Peraturan Pemerintah yang disebutkan diatas diikuti dengan diterbitkannya Peraturan Menteri Kesehatan yang mengatur tentang donor ASI, Penyediaan ruang pojok ASI di tempat kerja dan tempat sarana umum, tata cara penggunaan susu formula dan tata cara pengenaan sanksi administrative bagi tenaga kesehatan dan penyelenggara fasilitas pelayanan kesehatan (Yudhasmara, 2012).

Berdasarkan uraian diatas penulis tertarik untuk mengambil judul "Faktor-Faktor Yang Menyebabkan Kegagalan Ibu Dalam Memberikan ASI Eksklusif pada Bayi usia o-6 Bulan Di Wilayah Kerja Puskesmas Pejeruk".

\section{B. METODE PENELITIAN}

Desain penelitian yang digunakan dalam penelitian ini adalah deskriptif, penelitian deskriptif adalah suatu penelitian yang dilakukan untuk mendeskripsikan atau menggambarkan suatu fenomena yang terjadi dalam masyarakat. Penelitian ini menggunakan pendekatan waktu secara cross sectional dimana variabel diambil dalam kurun waktu yang sama (Notoatmodjo, 2012). Penelitian ini dilakukan pada tanggal 24-28 Juni 2016.Tempat penelitian ini dilakukan di Wilayah Kerja Puskesmas Pejeruk.

Variabel terikat dalam penelitian ini adalah kegagalan Ibu dalam memberikan ASI Ekslusif. Variabel bebas dalam penelitian ini adalah faktor-faktor yang berhubungan dengan pemberian ASI eksklusif yaitu faktor umur, tingkat pengetahuan, tingkat pendidikan, jumlah paritas dan dukungan orang terdekat (Notoatmodjo, 2012). Populasi dalam penelitian ini adalah semua ibu yang mempunyai bayi usia 6 bulan sampai 2 tahun yang tidak memberikan ASI Eksklusif di Wilayah Kerja Puskesmas Pejeruk sebanyak 51 orang. Sampel pada penelitian ini adalah 34 ibu yang mempunyai bayi usia 6 bulan sampai 2 tahun yang tidak memberikan ASI Eksklusif. Kriteria Ekslusi Sampel yaitu; 1) Ibu yang memberikan ASI Eksklusif di Wilayah Kerja Puskesmas Pejeruk; 2) Ibu menyusui yang tidak memberikan ASI Eksklusif di Wilayah Kerja Puskesmas Pejeruk yang tidak bersedia menjadi responden; 3) Ibu menyusui dengan kendala seperti sedang sakit, 
tunaaksara, pindah tempat tinggal, dan lain-lain. Tekhnik pengambilan sampel yang digunakan adalah purposive sampling. Dalam penelitian ini cara pengumpulan data yang digunakan adalah dengan menggunakan kuesioner. Uji bavariat dalam penelitian ini menggunakan chi square test.

\section{HASIL DAN PEMBAHASAN}

\section{Distribusi Responden Berdasarkan Umur Ibu}

TABEL 1.

Distribusi Jumlah Responden Menurut Kelompok Umur Di Wilayah Kerja Puskesmas Pejeruk

\begin{tabular}{ccc}
\hline Umur & $\mathbf{n}$ & $\mathbf{\%}$ \\
\hline$<20$ Tahun & 5 & 14,71 \\
$20-35$ Tahun & 20 & 58,82 \\
$>35$ Tahun & 9 & 26,73 \\
Total & 34 & 100
\end{tabular}

Sumber: Data Primer Penelitian Tahun 2016

Kelompok umur yang paling banyak mengalami kegagalan dalam memberikan ASI Eksklusif adalah responden dengan kelompok umur 20-35 tahun yaitu sebanyak 20 orang atau $58,82 \%$, sedangkan yang paling sedikit adalah kelompok umur $<20$ tahun tahun yaitu sebanyak 5 orang atau $14,71 \%$ dari 34 responden.

Hasil penelitian menunjukkan kegagalan pemberian ASI Eksklusif paling banyak terjadi pada responden berumur 20-35 tahun, hal ini dikarenakan $55 \%$ responden yang berumur 20-35 tahun merupakan primipara atau baru melahirkan satu kali jadi belum mempunyai pengalaman tentang menyusui, hasil penelitian ini didukung oleh penelitian yang dilakukan Nurul Fatimah pada tahun 2012 dengan judul "Faktor-Faktor yang Berhubungan dengan kegagalan Ibu Dalam Memberikan ASI Eksklusif Pada Bayi Di Puskesmas Bangetayu Semarang" didapatkan hasil bahwa dari 67 responden yang gagal memberikan ASI Eksklusif, terdapat 51 responden $(76,1 \%)$ yang berumur $20-35$ tahun, 9 responden dengan umur $>35$ tahun dan 7 responden dengan umur $<20$ tahun.

\section{Distribusi Responden Berdasarkan Jumlah Paritas}

\section{TABEL 2.}

Distribusi Jumlah Responden Menurut Jumlah Paritas Di Wilayah Kerja Puskesmas Pejeruk

\begin{tabular}{ccc}
\hline Paritas & n & \% \\
\hline Primipara & 16 & 47,06 \\
Multipara & 17 & 50 \\
Grande Multipara & 1 & 2,94 \\
Total & 34 & 100 \\
\hline Sumber: Data Primer Penelitian Tahun 2016
\end{tabular}

Responden yang banyak mengalami kegagalan dalam memberikan ASI eksklusif adalah responden dengan Multipara yaitu sebanyak 17 orang atau 50\%, sedangkan yang sedikit adalah responden dengan Grande Multipara yaitu 1 orang atau 2,94\%.

Hasil penelitian menunjukkan kegagalan pemberian ASI Eksklusif paling banyak terjadi pada responden dengan paritas multipara atau ibu yang pernah melahirkan 2 hingga 4 kali, danberdasarkan data yang didapat hal ini terjadi karena $76 \%$ ibu-ibu dengan paritas mulitpara memiliki riwayat kegagalan memberikan ASI secara eksklusif pada anak sebelumnya dan hal tersebut berlanjut pada bayi ibu selanjutnya, hasil penelitian ini didukung oleh penelitian yang dilakukan Fitria Ika dan Nalatia Riski pada tahun 2013 di UPT Puskesmas Banyudono I Kabupaten Boyolali dengan judul "Karakteristik Ibu Menyusui yang Tidak memberikan ASI Eksklusif Di UPT Puskesmas Banyudono I Kabupaten Boyolali”, dari 34 responden terdapat 19 responden atau 56\% dengan jumlah paritas multipara.

\section{Distribusi Responden Berdasarkan Tingkat Pendidikan}

TABEL 3.

Distribusi Jumlah Responden Menurut Tingkat

Pendidikan Di Wilayah Kerja Puskesmas Pejeruk

\begin{tabular}{ccc}
\hline $\begin{array}{c}\text { Tingkat } \\
\text { Pendidikan }\end{array}$ & $\mathbf{n}$ & $\mathbf{\%}$ \\
\hline $\begin{array}{c}\text { Pendidikan } \\
\text { Dasar }\end{array}$ & 17 & 50 \\
Pendidikan & 11 & 32,35 \\
Menengah & & 17,65 \\
Pendidikan & 6 & 100 \\
Tinggi & 34 &
\end{tabular}

Ibu dengan tingkat pedidikan rendah adalah responden terbanyak yang gagal memberikan ASI Eksklusif yaitu sebanyak 17 orang atau 50\%, sedangkan yang sedikit adalah ibu dengan tingkat pendidikan tinggi yaitu sebanyak 6 orang atau 17,65\%.

Pendidikan secara umum adalah segala upaya yang direncanakan untuk mempengaruhi orang lain baik individu maupun kelompok atau masyarakat sehingga mereka melakukan apa yang diharapkan oleh pelaku pendidikan. Semakin tinggi pendidikan semakin tinggi pula kemampuan dasar yang dimiliki seseorang, tingkat pendidikan dapat mendasari sikap ibu dalam menyerap dan mengubah informasi tentang ASI (Notoatmodjo, 2009).

Hal ini juga berlaku dalam pemberian ASI Eksklusif. Semakin tinggi pendidikan seseorang, maka ia akan mengambil keputusan yang baik, dan dalam hal ini yaitu memberikan ASI secara eksklusif kepada bayinya. Seseorang dengan latar belakang pendidikan dasar biasanya mengambil keputusan dan sikap yang salah karena kurangnya pendidikan atau edukasi yang didapat di bangku pendidikan, tentu saja hal ini juga mempengaruhi keputusan ibu dalam memberikan ASI secara eksklusif, sehingga ibu dengan latar belakang pendidikan dasar biasanya tidak memberikan ASI secara eksklusif (Nursalam, 2008).

Hasil penelitian yang didapat didukung oleh penelitian yang dilakukan Sandra Fikawati (2010) di Puskesmas Kecamatan Jagakarsa, Jakarta Selatan, kegagalan ASI eksklusif terutama terjadi pada ibu yang berpendidikan rendah yaitu sebanyak 14 responden, dan pada penelitian yang dilakukan oleh Laily Rahmah (2009), berdasarkan hasil analisis yang dilakukan melalui proses atribusi terhadap kegagalan pemberian ASI Eksklusif pada beberapa ibu hasilnya sebagian besar ibu yang gagal dalam 
memberikan ASI secara eksklusif adalah yang berpendidikan rendah.

Hasil ini juga didukung oleh penelitan yang dilakukan Loise Julianti Siagian (2011) di Kelurahan Bantang Kecamatan Medan Tembung dengan responden 34 orang dan hasilnya menunjukkan mayoritas responden dengan latar belakang pendidikan rendah yang gagal dalam memberikan ASI Eksklusif yaitu sebanyak 24 responden (70,6\%).

\section{Distribusi Responden Berdasarkan Tingkat Pengetahuan}

TABEL 4.

Distribusi Jumlah Responden Menurut Tingkat

Pengetahuan Di Wilayah Kerja Puskesmas Pejeruk

\begin{tabular}{ccc}
\hline Tingkat & n & \% \\
Pengetahuan & 16 & 47,06 \\
Baik & 15 & 44,12 \\
Cukup & 3 & 8,82 \\
Kurang & 34 & 100 \\
Total & Sumber: Data Primer Penelitian Tahun2016
\end{tabular}

Responden yang memiliki pengetahuan baik adalah yang paling banyak mengalami kegagalandalam memberikan ASI eksklusif yaitu sebanyak 16orang atau 47,06\%, sedangkan kelompok responden yang paling sedikit adalah kelompok responden yang memiliki pengetahuan kurang yaitu sebanyak 3 orang atau $8,82 \%$.

Pengetahuan merupakan hasil dari tahu dan ini terjadi setelah orang melakukan pengindraan terhadap suatu obyek tertentu. Pengindraan terjadi melalui pancaindra manusia yakni indra penglihatan, pendengaran, penciuman, rasa dan raba. Sebagian besar pengetahuan manusia diperoleh melalui mata dan telinga (Nursalam, 2008).

Tingkat pengetahuan responden ini diukur melalui daftar pertanyaan atau kuisioner yang diberikan. Ibu dengan pengetahuan baik adalah ibu yang paling banyak gagal dalam memberikan ASI Eksklusif pada bayinya, dalam hal ini pengetahuan baik yang dimaksud oleh Arikunto (2006) adalah ibu mempu menjawab 75\%-100\% dengan benar dari pertanyaan yang diberikan.

Pertanyaan nomor 1 tentang waktu dimulainya pemberian ASI pada bayi, 97\% ibu mampu menjawab dengan benar, dan pertanyaan nomor 2 tentang pemberian PASI (makanan pendamping ASI), 71\% ibu menjawab dengan benar, sedangkan untuk pertanyaan nomor 3 dan 4 tentang ASI Eksklusif, 97100\% ibu mampu menjawab dengan benar, selanjutnya pertanyaan nomor 5 tentang batas usia pemberian ASI, $100 \%$ ibu menjawab dengan benar, pertanyaan nomor 6 tentang alasan diberikan ASI Eksklusif, terdapat 94\% ibu yang mampu menjawab dengan benar, pertanyaan selanjutnya (nmor 7 dan 8) mengenai manfaat ASI, $71-94 \%$ ibu mampu menjawab dengan benar, untuk pertanyaan nomor 9 tentang PASI 94\% ibu mampu menjawab dengan benar, pertanyaan nomor 10 tentang susu formula (sufor), 79\% ibu menjawab dengan benar.

Pertanyaan nomor 11 tentang dampak bila bayi tidak mendapat ASI Eksklusif mampu dijawab dengan benar oleh 68\% ibu, pertanyaan nomor 12 tentang manfaat ASI bagi ibu mampu dijawab dengan benar oleh $100 \%$ ibu, dan untuk pertanyaan selanjutnya (nomor 13) tentang waktu pemberian ASI, 47\% ibu menjawab dengan benar, pertanyaan nomor 14 tentang aktifitas ibu menyusui, hanya $44 \%$ ibu yang menjawab dengan benar, dan pertanyaan selanjutnya (nomor 15) tentang ASI Perah dijawab dengan benar oleh 97\% ibu, pertanyaan nomor 16 tentang bayi yang tidak mau menyusu, hanya $38 \%$ ibu yang mampu menjawab dengan benar, dan untuk pertanyaan nomor 17 tentang waktu tidur bayi $>2$ jam dijawab dengan benar oleh $62 \%$ ibu, pertanyaan selanjutnya (nomor 18) mengenai ASI tidak lancar, hanya $44 \%$ ibu yang menjawab dengan benar, pertanyaan nomor 19 tentang persiapan ibu sebelum menyusui dijawab dengan benar oleh $88 \%$ ibu, dan untuk pertanyaan terakhir (nomor 20) mengenai hal yang dilakukan ibu menyusui saat sakit dijawab dengan benar oleh $59 \%$ ibu.

Responden yang memiliki pengetahuan baik, 8 diantaranya dengan pendidikan menengah, 4 ibu dengan pendidikan dasar dan 4 lainnya dengan pendidikan tinggi. Hasil observasi melalui wawancara terhadap ibu menyusui yang tidak memberikan ASI secara eksklusif namun berpengetahuan baik, mengakui bahwa mereka tahu mengenai ASI eksklusif melalui hasil pengukuran, tetapi tidak mau memberikan ASI itu sendiri. Hal ini disebabkan oleh karena faktor dari dalam diri ibu itu sendiri yang tidak ingin memberikan ASI eksklusif dengan kata lain tidak ada kemauan ibu untuk memberikan ASI Eksklusif pada bayinya. Ada yang mengatakan karena sibuk bekerja, takut akan payudara kendur dan lain sebagainya. Hal ini sesuai dengan pendapat Notoadmojo (2010) yang menyatakan bahwa ada orang yang tingkat pengetahuannya hanya tahu saja, tetapi tidak bisa mempraktikkannya.

Banyak ibu dengan pengetahuan baik yang gagal memberikan ASI Eksklusif, hal ini didukung oleh penelitian yang dilakukanAnisa Wulandari pada tahun 2008 dengan Judul "Beberapa Faktor Yang Berhubungan Dengan Kegagalan Pemberian ASI Eksklusif Oleh Ibu Bayi Di Wilayah Kerja Puskesmas Lamper Tengah Kota Semarang Tahun 2008" didapatkan hasil bahwa dari 70 ibu yang memiliki bayi usia 7-12 bulan yang gagal memberikan ASI Eksklusif, diantaranya terdapat $62,91 \%$ ibu yang memiliki pengetahuan baik.

Hal ini, memberikan gambaran bahwa tingkat pengetahuan yang baik bukanlah jaminan bagi ibu untuk menyusui bayinya secara Ekskluisif jika tidak diikuti dengan kemauan yang tinggi.

\section{Distribusi Responden Berdasarkan Dukungan Orang Terdekat}

TABEL 5 .

Distribusi Jumlah Responden Berdasarkan

Dukungan Orang Terdekat Di Wilayah Kerja Puskesmas Pejeruk

\begin{tabular}{ccc}
\hline $\begin{array}{c}\text { Dukungan } \\
\text { Orang } \\
\text { Terdekat }\end{array}$ & $\mathbf{n}$ & $\mathbf{\%}$ \\
\hline Baik & 7 & 20,59 \\
Cukup & 25 & 73,53 \\
Kurang & 2 & 5,88 \\
Total & 34 & 100 \\
\hline Sumber: Data Primer Penelitian Tahun2016
\end{tabular}


Responden yang banyak mengalami kegagalan dalam memberikan ASI Eksklusif yaitu ibu dengan dukungan yang cukup yaitu sebanyak 25 orang atau $73,53 \%$, sedangkan yang sedikit mengalami kegagalan adalah ibu dengan dukungan yang kurang yaitu sebanyak 2 orang atau 5,88\%. Dukungan orang terdekat merupakan suatu dukungan oleh orangorang tertentu terhadap suatu kegiatan guna menumbuhkan dan meningkatkan semangat dan rasa percaya diri (Hubertin, 2010). Setiap orang membutuhkan bantuan afeksi dari orang lain. Dukungan ini berupa simpatik dan empati, cita, kepercayaan, dan penghargaan.

Dengan demikian, seseorang yang menghadapi persoalan merasa dirinya tidak menanggung beban sendiri, tetapi masih ada orang lain yang memperhatikan, mau mendengar segala keluhannya, bersimpati, dan empati terhadap persoalan yang dihadapi, bahkan mau membantu memecahkan masalah yang dihadapinya (Hubertin, 2010). Keputusan untuk memberikan ASI sering dipengaruhi oleh keluarga seperti suami dan orang tua, teman dan lingkungan sosial ibu dari pada pengetahuan ibu. Dukungan mereka telah terbukti berpengaruh terhadap pemberian ASI Eksklusif (Hubertin, 2010).

Hasil penelitian ini, ibu yang banyak gagal memberikan ASI Eksklusif adalah ibu yang mendapatkan dukungan yang cukup dari orangorang terdekatnya yaitu sebanyak 25 orang, dimana 11 diantaranya dengan tingkat pendidikan dasar, 10 lainnya dengan tingkat pendidikan menengah dan 4 lainnya dengan tingkat pendidikan tinggi. Hasil penelitian yang didapat didukung oleh penelitian yang dilakukan oleh Tia Komala Sari pada tahun 2015 diPuskesmas Pringapus Kabupaten Semarang, kegagalan terbanyak ASI eksklusif terjadi pada ibu dengan dukungan yang cukup, yaitu sebanyak 40 responden (43,5\%) dari 92 responden. Dengan dukungan kurang sebanyak 29 responden (31,5\%) dan dukungan yang baik sebanyak 23 responden (25\%).

\section{Analisis Bivariat}

TABEL 6.

Analisis dengan menggunakan uji chi square

\begin{tabular}{|c|c|c|c|c|c|c|c|c|c|}
\hline \multirow{2}{*}{$\begin{array}{l}\mathrm{N} \\
\mathrm{o}\end{array}$} & \multirow{2}{*}{ Variabel } & \multirow{2}{*}{ Kategori } & \multicolumn{2}{|c|}{$\begin{array}{l}\text { Tidak ASI } \\
\text { eksklusif }\end{array}$} & \multicolumn{2}{|c|}{$\begin{array}{c}\text { ASI } \\
\text { eksklusif }\end{array}$} & \multicolumn{2}{|r|}{ Total } & \multirow{2}{*}{$\begin{array}{c}P \\
\text { value }\end{array}$} \\
\hline & & & $\mathrm{F}$ & $\%$ & $\mathrm{~F}$ & $\%$ & $\mathrm{~N}$ & $\%$ & \\
\hline 1. & Umur & $\begin{array}{l}<20 \\
\text { tahun }\end{array}$ & 3 & $27,3 \%$ & 2 & $8,7 \%$ & 5 & $14,7 \%$ & \multirow{6}{*}{0,691} \\
\hline \multirow{5}{*}{2.} & \multirow{5}{*}{ Paritas } & $\begin{array}{l}20-35 \\
\text { tahun }\end{array}$ & 5 & $45,5 \%$ & 15 & $65,2 \%$ & 20 & $58,8 \%$ & \\
\hline & & $\begin{array}{l}>35 \\
\text { tahun }\end{array}$ & 3 & $27,3 \%$ & 6 & $26,1 \%$ & 9 & $26,5 \%$ & \\
\hline & & $\begin{array}{l}\text { Primi- } \\
\text { para }\end{array}$ & 6 & $54,5 \%$ & 10 & $43,5 \%$ & 16 & $47,1 \%$ & \\
\hline & & $\begin{array}{l}\text { Multi- } \\
\text { para }\end{array}$ & 5 & $45,5 \%$ & 12 & $52,2 \%$ & 17 & $50 \%$ & \\
\hline & & $\begin{array}{l}\text { Grande } \\
\text { multi- } \\
\text { para }\end{array}$ & o & $\mathrm{o} \%$ & 1 & $100 \%$ & 1 & $2,9 \%$ & \\
\hline \multirow[t]{2}{*}{3 . } & \multirow[t]{2}{*}{$\begin{array}{l}\text { Pendidi } \\
\text { kan }\end{array}$} & SD & 6 & $54,5 \%$ & 11 & $47,8 \%$ & 17 & $50 \%$ & \multirow[t]{2}{*}{0,663} \\
\hline & & $\begin{array}{l}\text { SMP } \\
\text { SMA }\end{array}$ & $\begin{array}{l}4 \\
1\end{array}$ & $\begin{array}{c}36,4 \% \\
9,1 \%\end{array}$ & $\begin{array}{l}7 \\
5\end{array}$ & $\begin{array}{l}30,4 \% \\
21,7 \%\end{array}$ & $\begin{array}{c}11 \\
6\end{array}$ & $\begin{array}{l}32,4 \% \\
17,6 \%\end{array}$ & \\
\hline \multirow[t]{2}{*}{4} & \multirow{2}{*}{$\begin{array}{l}\text { Pengeta } \\
\text { huan }\end{array}$} & Kurang & 2 & $18,2 \%$ & 1 & $4,3 \%$ & 3 & $8,8 \%$ & \multirow[t]{2}{*}{0,240} \\
\hline & & Cukup & 3 & $27,3 \%$ & 12 & $52,2 \%$ & 15 & $44,1 \%$ & \\
\hline
\end{tabular}

\begin{tabular}{|c|c|c|c|c|c|c|c|c|c|}
\hline & & Baik & 6 & $54,3 \%$ & 10 & $43,5 \%$ & 16 & $47,1 \%$ & \\
\hline \multirow[t]{3}{*}{5} & \multirow[t]{3}{*}{$\begin{array}{l}\text { Dukun } \\
\text { gan } \\
\text { orang } \\
\text { terdek } \\
\text { at }\end{array}$} & Kurang & 2 & $\begin{array}{r}18,2 \\
\%\end{array}$ & o & o\% & 2 & $5,9 \%$ & \multirow[t]{3}{*}{$\begin{array}{l}0,00 \\
0\end{array}$} \\
\hline & & Cukup & 3 & $27,3 \%$ & 22 & $95,7 \%$ & 25 & $73,5 \%$ & \\
\hline & & Baik & 6 & $54,5 \%$ & 1 & $4,3 \%$ & 7 & $20,6 \%$ & \\
\hline
\end{tabular}

\section{SIMPULAN DAN SARAN}

Berdasarkan hasil penelitian dan pembahasan maka dapat ditarik beberapa Simpulan sebagai berikut:

1. Faktor umur sebagian besar responden yang gagal memberikan ASI secara Eksklusif adalah yang berusia 20 - 35 tahun yaitu 20 orang atau $58,82 \%$.

2. Faktor paritas sebagian besar responden yang gagal memberikan ASI secara Eksklusif adalah responden dengan paritas multipara yaitu 17 orang atau $50 \%$.

3. Faktor pendidikan sebagian besar responden yang gagal memberikan ASI secara Eksklusif adalah responden dengan pendidikan rendah yaitu 17 orang atau $50 \%$.

4. Faktor pengetahuan sebagian besar responden yang gagal memberikan ASI secara Eksklusif adalah responden dengan tingkat pengetahuan baik yaitu 16 orang atau $47,06 \%$.

5. Faktor dukungan orang terdekat sebagian besar responden yang gagal memberikan ASI secara Eksklusif adalah responden dengan dukungan yang cukup yaitu 25 orang atau $73,53 \%$.

6. Terdapat hubungan yang bermakna antara dukungan orang terdekat dengan Kegagalan Ibu Dalam Memberikan Asi Ekslusif Pada Bayi Usia o-6 Bulan Di Wilayah Kerja Puskesmas Pejeruk dimana nilai $p$ value $0.000(p<0.05)$.

Saran dalam penelitian ini adalah diharapkan instansi kesehatan khususnya Puskesmas Pejeruk dapat selalu memberikan penyuluhan mengenai ASI Eksklusif dengan menggunakan bahasa yang mudah dimengerti oleh masyarakat awam dan mengikutsertakan keluarga atau orang terdekat klien agar dapat menekan angka kegagalan ASI Eksklusif dan dapat memenuhi angka yang ditargetkan oleh Depkes RI.

\section{UCAPAN TERIMA KASIH}

Tim penulis mengucapkan terima kasih kepada LPPM UM Mataram yang telah mendanai penelitian ini.

\section{DAFTAR RUJUKAN}

[1] Ambarwati. Asuhan KebidananNifas. Mitra Cendikia, Yogyakarta, 2008.

[2] Roesli, U. Panduan Praktis Menyusui, Pustaka Bunda, Jakarta 2009.

[3] Hubertin, S., Buku Saku Untuk Bidan.Buku Kedokteran EGC, Jakarta, 2010. 
[4] Notoatmodjo, S. Promosi Kesehatan dan Ilmu Perilaku, PT. Rineka Cipta, Jakarta, 2010.

[5] Notoatmodjo, S. 2012. Metodologi Penelitian Kesehatan, PT.Rineka Cipta, Jakarta, 2010.

[6] Nursalam, Konsep dan Penerapan Penelitian Ilmu Keperawatan : Pedoman Skripsi, Tesis, dan Instrumen Penelitian Keperawatan, Salemba Medika, Jakarta, 2008.

[7] Fatimah, Nurul, Faktor-Faktor yang Berhubungan dengan kegagalan Ibu Dalam Memberikan ASI Eksklusif Pada Bayi Di Puskesmas Bangetayu Semarang, Semarang, 2012.

[8] Fikawati, S., Faktor yang Mempengaruhi Kegagalan ASI Eksklusif di Wilayah Kerja Puskesmas Kecamatan Jagakarsa. Jakarta Selatan, 2010.

[9] Fitria, Nalatia, Karakteristik Ibu Menyusui yang Tidak memberikan ASI Eksklusif Di UPT Puskesmas Banyudono I Kabupaten Boyolali. Jurnal Kesehatan Andalas Vol. 2 No. 2., 2013.

[10] Rahmah, L., Faktor-Faktor yang Berhubungan dengan Status Pemberian ASI Eksklusif Kepada Bayi di Puskesmas Ilung Kecamatan Batang Alai Utara Kabupaten Hulu Sungai Tengah. Banjarmasin, 2009.

[11] Sari, Tia K., Faktor-Faktor yang Mempengaruhi Pemberian ASI Eksklusif pada Ibu menyusui, Semarang, 2015.

[12] Siagian, Loise J., Faktor Penyebab Gangguan Pemberian ASI Eksklusif Pada Bayi di Kelurahan Bantang Kecamatan Medan Tembung. Medan, 2011.

[13] Wulandari, A., Beberapa Faktor Yang Berhubungan Dengan Kegagalan Pemberian ASI Eksklusif Oleh Ibu Bayi Di Wilayah Kerja Puskesmas Lamper Tengah Kota Semarang Tahun 2008, Semarang, 2008.

[14] Depkes RI, 2014. Survey demografi Kesehatan Indonesia.

[15] Dikes NTB, 2014. Profil Kesehatan Provinsi NTB.

\section{PROFIL PENULIS UTAMA}

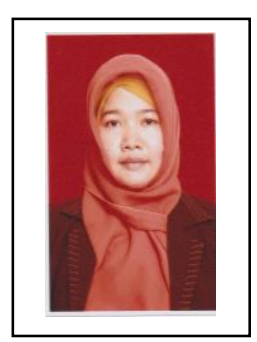

Nama: Cahaya Indah Lestari, S.ST

Riwayat Pendidikan:

D-III Kebidanan Poltekkes Kemenkes Mataram

(2007)

D-IV Kebidanan Poltekkes Kemenkes Mataram

(2011)

Alamat: Mataram, Nusa Tenggara Barat

Penelitian Lain:

Hubungan umur wanita dengan kejadian kanker payudara di Rumah Sakit Umum Propinsi NTB tahun 2013, Gambaran tingkat pengetahuan ibu nifas tentang teknik menyusui yang benar di wilayah kerja Puskesmas Dasan Cermen tahun 2014, Pengaruh penyuluhan teknik pijat bayi terhadap pengetahuan dan keterampilan pijat bayi pada ibu di Dusun Pandanan tahun 2015 